\title{
Novel MMP-inhibiting peptides for stabilizing
}

atherosclerotic plaques

Anahita Abdalia ${ }^{a}$ Helena Macut ${ }^{b}$, Sara Pellegrino ${ }^{b}$, Carlo de Dominicis $^{c}$, Matteo Zandac, Maria Luisa Gelmi ${ }^{b}$, Stefano Bellosta ${ }^{a}$

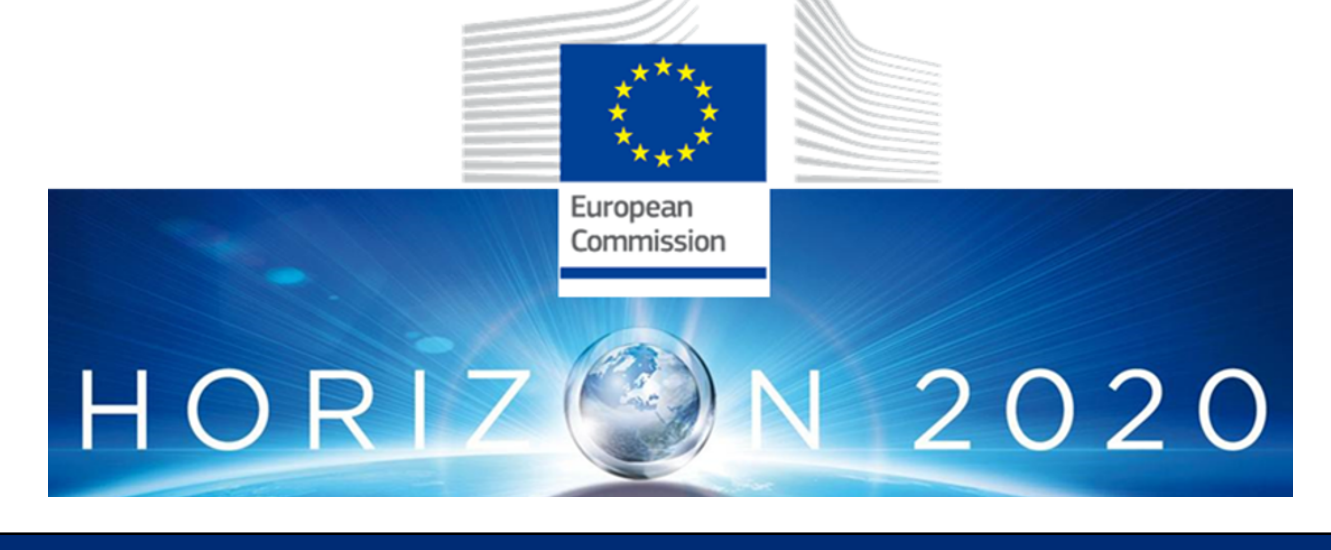

a.Dept. of Pharmacological and Biomolecular Sciences, Milan, University of Milan

b.Dept. of Pharmaceutical Sciences, Milan, University of Milan

c.Institute of Medical Sciences, Aberdeen, University of Aberdeen

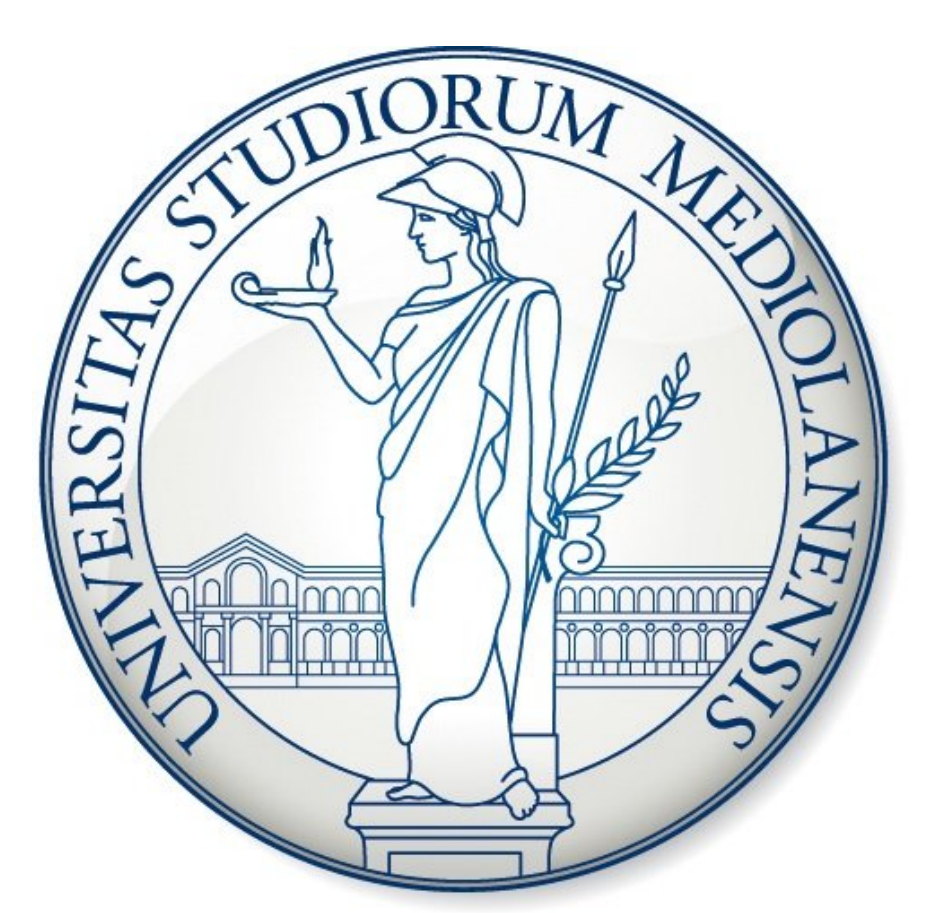

UNIVERSITÀ DEGLI STUDI DI MILANO E-mail: anahita.abdali@unimi.it

\section{Introduction}

The glycolytic enzyme 6-Phosphofructo-2-kinase/fructose-2,6-bisphosphatase, isoform 3 (PFKFB3) has been shown to be an effective target in angiogenic models by reducing the migration and proliferation of endothelial cells (ECs) and thus angiogenesis. Matrix-degrading metalloproteases (MMPs) play an essential role in angiogenesis as they degrade extracellular matrix components to enable endothelial cell (EC) migration.

We studied the in vitro effects of the commercially available PFKFB3 inhibitor, 3-(3-pyridinyl)-1(4-pyridinyl)-2-propen-1-one (3PO), and newly designed PFKFB3-binding compounds on MMP activity and wound-healing capacity.

\section{Aim}

To investigate the effect of novel PFKFB3-binding compounds on endothelial migration, proliferation and angiogenesis.

Following this, we will examine the pharmaceutical potential of PFKFB3 blockage on atherosclerotic plaque progression and stability.

Inhibition of wound closure of Endothelial Cells by PFKFB3-binding compounds

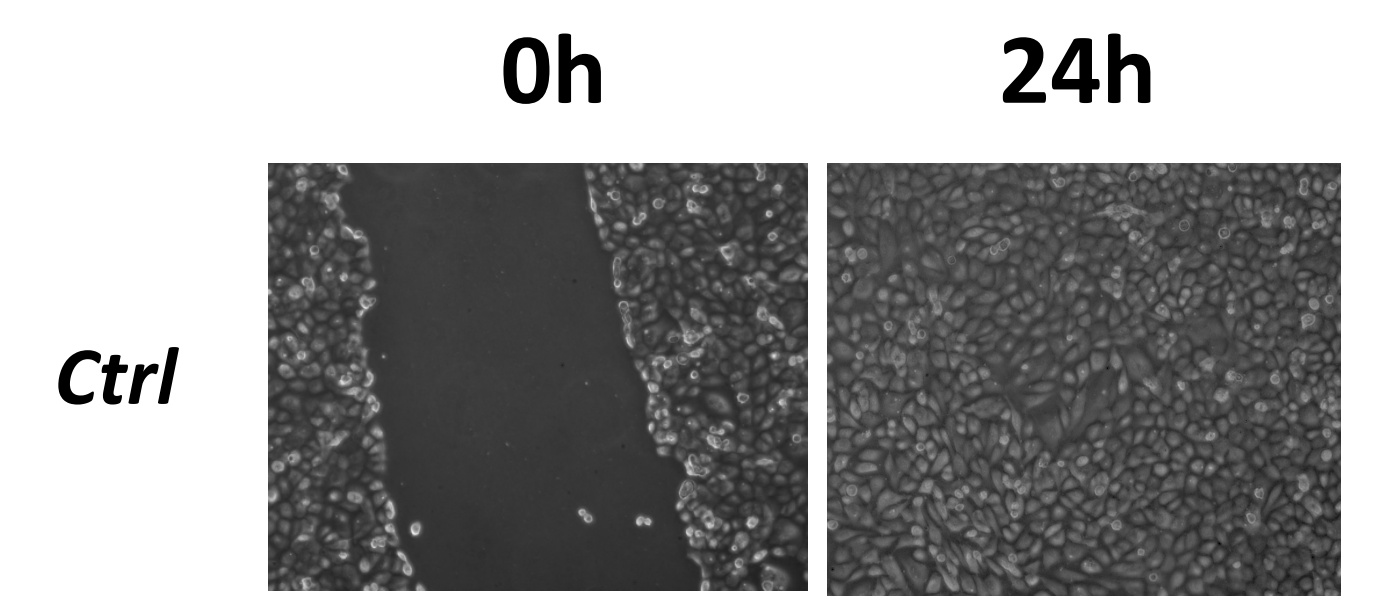

Endothelial cell line: EA.hy926
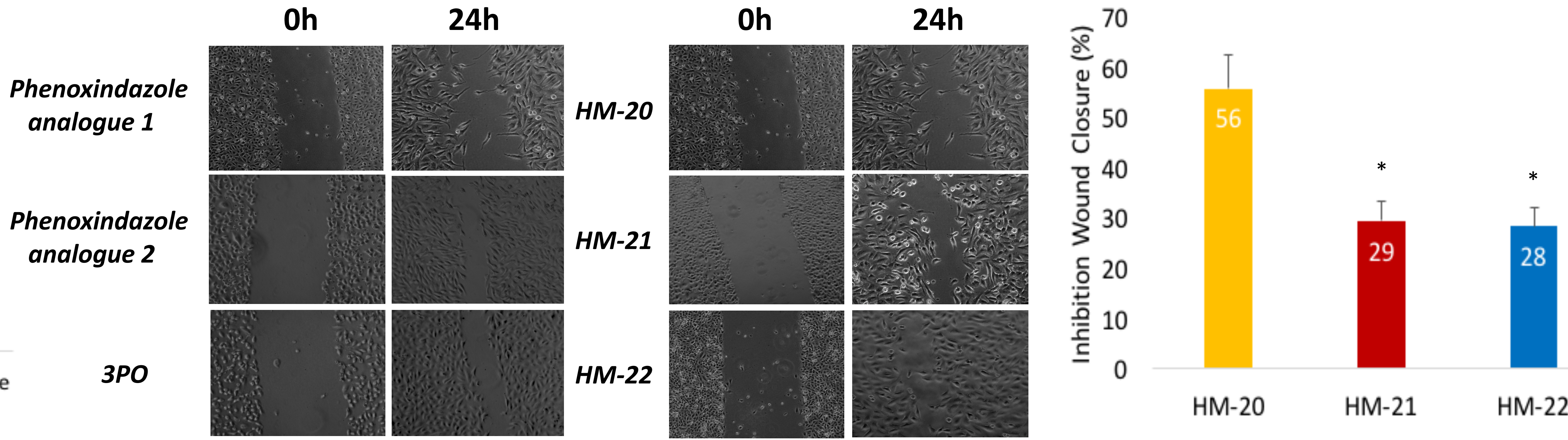

Decreased MMP-9 and MMP-2 activity in Endothelial Cells by PFKFB3-binding compounds

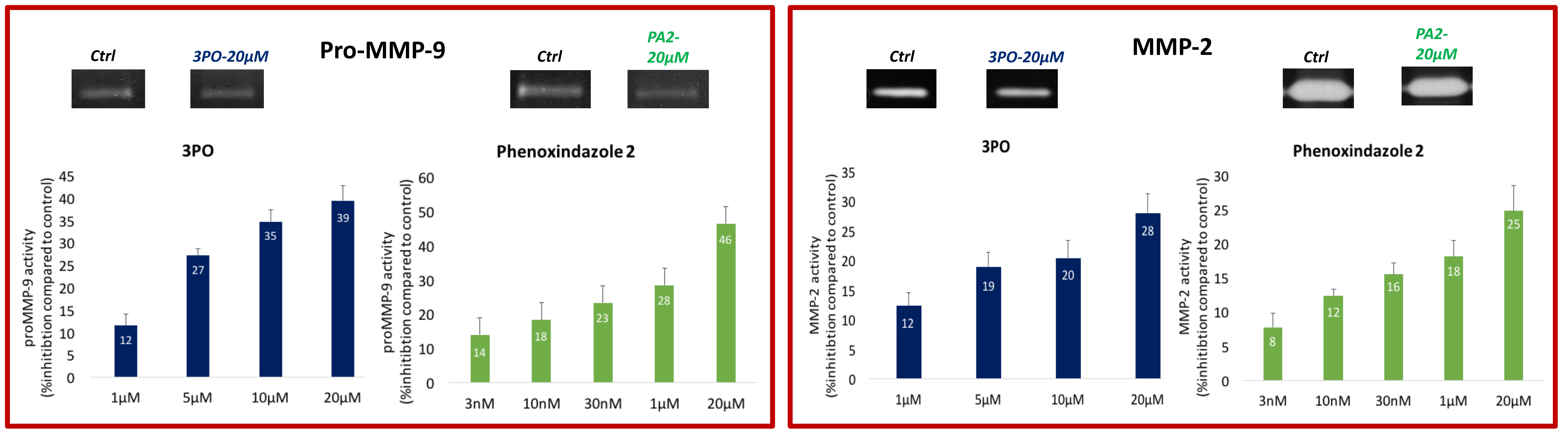

Affinity of PFKFB3-binding compounds

\begin{tabular}{|c|c|c|c|c|c|}
\hline & & Structure & $M W$ & Kd & $\begin{array}{c}\text { IC }_{50} \\
\text { Kinase }\end{array}$ \\
\hline & 3-PO & & 210.2 & $22 \mu \mathrm{M}$ & $T B D$ \\
\hline \multirow{2}{*}{$\begin{array}{l}\text { Boyd, S. et al. J. Med. Chem. } \\
\text { 58, 3611-3625 (2015) }\end{array}$} & $\begin{array}{l}\text { Phenoxindazole } \\
\text { analogue } 1\end{array}$ & & 517.5 & $3 \mu \mathrm{M}$ & $30 \mathrm{nM}$ \\
\hline & $\begin{array}{c}\text { Phenoxindazole } \\
\text { analogue } 2\end{array}$ & & 456.6 & $T B D$ & $5 \mu \mathrm{M}$ \\
\hline \multirow{3}{*}{$\begin{array}{l}\text { In silico design and } \\
\text { synthesis }\end{array}$} & HM-20 & & 686.8 & $7 \mu \mathrm{M}$ & $N D$ \\
\hline & HM-21 & & 635.8 & $20 \mu \mathrm{M}$ & $N D$ \\
\hline & HM-22 & & 424.5 & $0.2 \mu \mathrm{M}$ & $N D$ \\
\hline
\end{tabular}

\section{Conclusion}

Novel compounds, such as PA2 efficiently inhibit endothelial migration, therefore having a potential to be used as inhibitors of angiogenesis, a process detrimental for atherosclerotic plaque stability.

Additionally, targeting PFKFB3 offers a gateway to reduce MMP activity and consequently stabilize atherosclerotic plaques. 